Research Article

\title{
Mutual Interference and Coupling Response of Multicylinder Vibration among Combine Harvester Co-Frame
}

\author{
Zhong Tang (D, Haotian Zhang, Yuepeng Zhou, and Yu Li \\ School of Agricultural Equipment Engineering, Jiangsu University, Zhenjiang 212013, Jiangsu, China \\ Correspondence should be addressed to Zhong Tang; tangzhong2012@126.com
}

Received 29 January 2019; Revised 27 April 2019; Accepted 16 May 2019; Published 16 June 2019

Academic Editor: Nuno M. Maia

Copyright ( $\odot 2019$ Zhong Tang et al. This is an open access article distributed under the Creative Commons Attribution License, which permits unrestricted use, distribution, and reproduction in any medium, provided the original work is properly cited.

\begin{abstract}
Unbalanced vibrations of axial threshing cylinders on a combine harvester were coupled to each other through a frame. The intensified unbalanced vibration will shorten the working life of the axial threshing cylinder. In this paper, the theoretical modes of the axial threshing cylinder were carried out by using finite element analysis software ANSYS. The axis trajectory and speed fluctuation of the axial threshing cylinder under no-load state and threshing state were tested and analyzed. According to the amplitude and axis trajectory of the transmission shaft, as well as the variation law of the axial threshing cylinder speed, the influence of rice straw on the vibration under the threshing state was revealed. The rotation speeds of cylinder I and cylinder III were adjusted, and the amplitude of cylinder II transmission shaft was analyzed when cylinder II was under stable condition. Then the disturbance and coupling relationships among the unbalanced vibration of axial threshing cylinders were compared. Test results showed that the rotational frequency of the axial threshing cylinder was not in its resonance interval at rated speed. When the axial threshing cylinder was threshing, the horizontal amplitude increased by $0.366 \mathrm{~mm}$. The vertical amplitude increased by $0.697 \mathrm{~mm}$. The speed decreased from $763 \mathrm{rpm}$ to about $750 \mathrm{rpm}$. The rotational frequency of the axial threshing cylinder would not cause the resonance. With the feeding of rice, the amplitude of the axial threshing cylinder increased slightly and the operating speed was lower than the rated speed. The unbalanced vibration of the axial threshing cylinder transmitted along the frame and coupled with each other, causing the vibration of the axial threshing cylinder to be intensified.
\end{abstract}

\section{Introduction}

During the rice threshing process, an axial threshing cylinder was wound and restrained by the rice straw, which caused a deviation between the center of mass and the centroid of the axial threshing cylinder. When the axial threshing cylinder rotated, it produced unbalanced vibration and reduced its life. The unbalanced vibration of the axial threshing cylinder transmitted along the frame. The unbalanced vibration among axial threshing cylinders disturbed and coupled with each other and then caused the structural resonance and even the working failure of the axial threshing cylinder.

The axial threshing cylinder often exhibited speed fluctuation and unstable load during the threshing process. It could produce nonstationary vibration signals. The vibration signals could provide abundant system dynamics information for monitoring and diagnosing the state of the rotating machine [1]. There were many rotating mechanisms in a rice combine harvester, but the internal structures were not easy to observe. The vibration characteristics could be analyzed by vibration signals. Gao et al. studied the vibration characteristics of a crawler full-feed combine harvester under different feed rates in field [2]. It was found that the vibration of the combine harvester intensified under working condition, and axial threshing cylinders were the main sources of excitation in the machine's horizontal direction. Excessive vibration could cause the driver to feel uncomfortable during harvesting process. Kociolek et al. studied the vibration transmission of a four-wheeled motor vehicle while it was operated on a farmland. He found that resonant frequencies may amplify vibration transmitted to the head/neck and increase risk of musculoskeletal disorders [3]. In order to reduce the 
vibration of the combine harvester under working condition, many scholars improved the structure of a combine harvester. Yao et al. analyzed the impact of excitation frequencies of key components and pavement roughness on a corn combine harvester and optimized the structure of the frame [4]. Li et al. performed a modal test on a compression device of a combine harvester and found that the second-order modal frequency of the compression device was within the excitation frequency range of the axial threshing cylinder. The resonance phenomenon was obvious under working condition [5]. Zhang calculated the optimal combination of weight distribution position and mass on the cutting structure and solved the vibration problem of the cutting structure of the crawler combine harvester [6]. Chuan-Udom developed 3 types of new cutter bar drivers to reduce the vibration of the rice combine harvester [7]. It can be seen that the structural vibration of the combine harvester has attracted the attention of a large number of scholars. There were also many reports on the structural vibration of the combine harvester.

There were numerous rotating mechanisms in a combine harvester, and the rotating mechanisms were prone to be speed fluctuation during high-speed operation. Yoshino et al. suppressed the vibration of a machine's rotating shaft by changing the transmission shaft speed and enabled easy setting of the fluctuation parameters [8]. Solmaz and Karabulut established a mathematical model for engine speed fluctuations and studied the effects of pressure changes in the cylinder on engine speed fluctuation [9]. The unbalanced vibration of the rotor could be analyzed by the rotational speed fluctuation. Felber and Pfeiffer invented a device for identifying the rotor's rotational speed fluctuation characteristics. They described its local vibration mode by analyzing the rotor local variables [10]. Yang et al. analyzed the vibration response of the rotor during acceleration and deceleration and proposed a method for parameterized TFA analysis of nonstationary vibration signals of variable speed rotating machinery [11]. Wang et al. applied the statistical energy analysis method to establish the relationship between the linear vibration energy coupling strength and mode density [12]. Brischetto et al. used the three-dimensional exact solution and twodimensional numerical solution to analyze an axial threshing cylinder free vibration [13]. Zhou et al. analyzed the modality of the threshing cylinder and verified reliability of the structure by ANSYS [14]. The axial threshing cylinder was an important part of the combine harvester. However, the rotation of the threshing cylinder would cause the frame to vibrate and reduce the frame reliability. In particular, there were few reports on the vibration state and cause for vibration of an axial threshing cylinder under working condition.

Because the axial threshing cylinder was wound and restrained by rice straw, it produces unbalanced vibration during the rice threshing process. In order to suppress the unbalanced vibration during the rotor rotation, $\mathrm{Wu}$ studied the influence of the motor eccentricity on the dynamic response of the spindle. The results showed that the motor eccentricity had a significant effect on the spindle vibration. It greatly reduced the machining quality $[15,16]$. Eissa and Saeed proposed a controller with a $1: 1$ internal resonance coupled to the system to control the rotor system nonlinear vibration [17]. Liu and Shao offered a new vibration modeling method for lubricated roller bearings that provided precise pulses from the bearing race surface [18]. Lee et al. simulated the structural vibration of the self-oscillating cylinder and rigid fixed cylinder during eddy current coupling [19]. Bourguet and Lo Jacono explored the eddy current vibration law generated by the forced-rotating cylinder through simulation analysis [20]. $\mathrm{Li}$ and Zhu investigated the coupling mechanism between shafting vibration and stiffness in a pumping unit. A computational principle and method were proposed to calculate the stiffness of a vertical water pump unit based on a lumped parameter model [21]. So far, there were few studies on the unbalanced vibration of the axial threshing cylinder during the threshing process and the mutual disturbance and coupling among the unbalanced vibration of the co-frame multicylinder. During the threshing process, the mutual disturbance and coupling among axial threshing cylinders increased the unbalanced vibration. However, the vibration mutual interference and coupling characteristics among the co-frame multicylinders were not clear.

There were 3 parallel threshing cylinders on the multicylinder test bench. Cylinder II located in the middle was chosen as the subject investigated in this paper. The influence of two adjacent threshing cylinders on the same frame to cylinder II was studied. Firstly, the basic characteristic of cylinder II was studied. The modal analysis of the axial threshing cylinder was carried out by the finite element analysis software ANSYS Workbench. The axis trajectory and the speed fluctuation of the axial threshing cylinder under the no-load state and the threshing state were tested and analyzed. According to the amplitude and axis trajectory of the transmission shaft, as well as the speed fluctuation law of the axial threshing cylinder, the influence law of vibration caused by rice straw entanglement under the threshing state is revealed. Then by analyzing the bearing housing amplitude variation and the change of the transmission shaft axis trajectory, the mutual interference and coupling characteristics among the vibration of the co-frame multicylinder were revealed.

\section{Materials and Methods}

2.1. Co-Frame Multicylinder Test Bench in Rice Threshing. This paper took the co-frame multicylinder test bench as the subject to investigate. The test bench consisted of a conveyor belt, conveying trough, tangential threshing cylinder (cylinder I), axial threshing cylinder I (cylinder II), and axial threshing cylinder II (cylinder III). Figure 1(a) showed the array of structure drawing of the co-frame multicylinder test bench. Rice entered cylinder I, cylinder II, and cylinder III in sequence along the conveying trough. The cylinders were arranged in parallel on the frame. The position relationship among the cylinders is shown in Figure 1(b). 


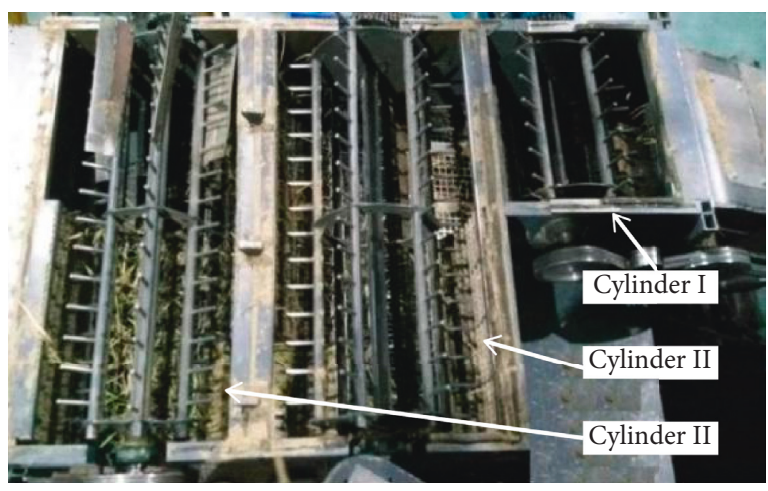

(a)

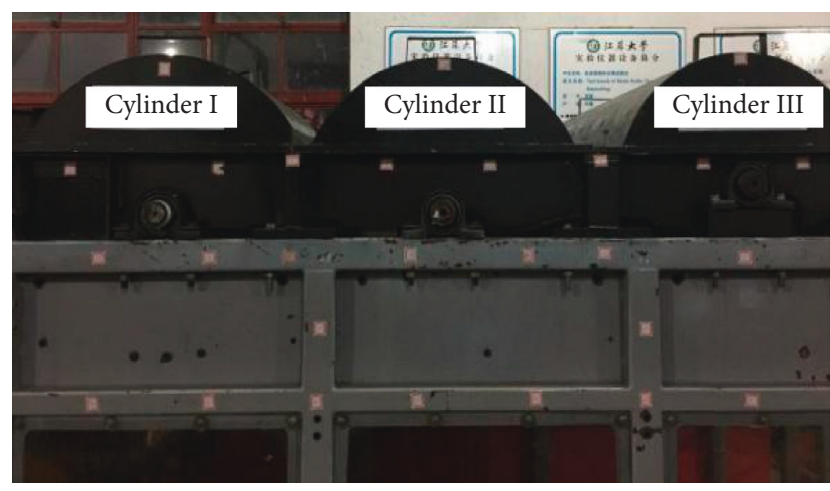

(b)

Figure 1: Co-frame multicylinder test bench. (a) The array structure of three cylinders. (b) The position relationship among the cylinders.

2.2. Finite Element Analysis of Axial Threshing Cylinder. ANSYS Workbench is software for simulating structural statics, structural dynamics, rigid body dynamics, and fluid dynamics of mechanical structures in a cosimulation environment. A 3D model of cylinder II was created by Pro/E and saved as STEP format. Then the model was introduced into the ANSYS Workbench for theoretical analysis under no-load state. Fillets and small holes had little effect on the simulation results that could slow down the simulation speed. Therefore, they need to be simplified before imported into the ANSYS Workbench.

The finite element model of cylinder II built in Pro/E is shown in Figure 2(a). Figure 2(b) shows the imported model of cylinder II.

The material properties of cylinder II need to be set before the finite element analysis. Cylinder II was made of Q235 ordinary carbon structural steel. The modulus of elasticity was $210 \mathrm{GPa}$. Poisson's ratio was 0.3 . The density and yield strength were $7850 \mathrm{~kg} / \mathrm{m}^{3}$ and $235 \mathrm{MPa}$, respectively.

Meshing was the most important step in preprocessing of finite element simulation. The increase in the number and density of meshes could lead to more accurate simulation results, but the solution time would increase accordingly. The solution efficiency would be affected. Bermejo et al. compared two practical methodologies for modeling the collapse of reinforced concrete structures. The results showed the continuum finite element model was more accurate for interpreting local failure but have an excessive computational cost [22]. Excessive mesh size led to the decrease in the quality of the meshes, resulting in inaccurate calculation results and even aborting the calculation. When setting the meshing parameters, the accuracy of the simulation results and the time required for the simulation should be considered comprehensively. The automatic method was used for meshing of cylinder II. The meshing method was automatically selected according to the shape of the entity. The sweepable entities were preferentially divided by the sweep method, and the nonscanning entities were divided by the patch conforming algorithm. Because cylinder II had a minimum structural thickness of $4 \mathrm{~mm}$, the mesh size was $4 \mathrm{~mm}$. The number of generated meshes was 530,715, and the number of nodes was $1,013,521$. The meshing result is shown in Figure 3(a).

The modality was the inherent property and characteristic of cylinder II. When cylinder II was threshing, the modality of cylinder II was changed by restrictions. The modality restricted under no-load state is shown in Figure 3(b). Both axial ends of cylinder II were cylindrical constraint positions shown as Point A and Point B. Cylinder II can only rotate around its transmission shaft. In addition to Point $\mathrm{A}$ and Point B, cylinder II was also subjected to the resistance of the rice under the state of containing rice. The transmission shaft was subjected to the torque.

\subsection{Analysis of Threshing Vibration Response of Axial} Threshing Cylinder. Due to the uneven material of the axial threshing cylinder and unavoidable error factors such as cutting and assembly errors, the center of mass and the centroid of the axial threshing cylinder were not coincident. There would be a certain eccentricity between them. The eccentricity of the axial threshing cylinder would generate centrifugal force. It could cause vibration and aggravate the wear of the bearing. The axial threshing cylinder could be caused to go out of order at high speed. The assembled axial threshing cylinder was subjected to dynamic balance test before delivery. The amplitude of the transmission shaft was always within safe limits when the axial threshing cylinder was under no-load state. The axial threshing cylinder would not break down due to long-term severe vibration. To easily correct the unbalancing condition of the crankshaft system, Zhang and Zhang designed the unbalancing adjustment equipment based on the flywheel structure. The balancing effect of the field dynamic balancing system has been verified by field experiments [23].

The rice wounds on the axial threshing cylinder and rotates with it together during the threshing process, so the axial threshing cylinder that had passed the dynamic balance test produces an eccentricity again and increases the probability of failure of the axial threshing cylinder. Bai and Zhang analyzed the mechanical unbalanced forces and the unbalanced magnetic force on the rotor and found that 


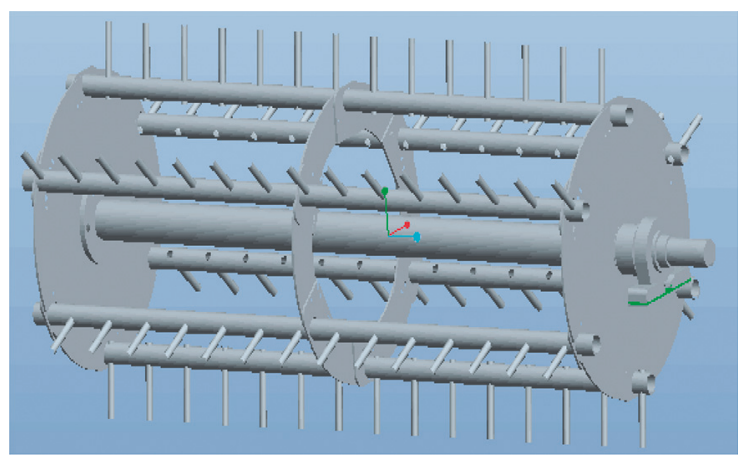

(a)

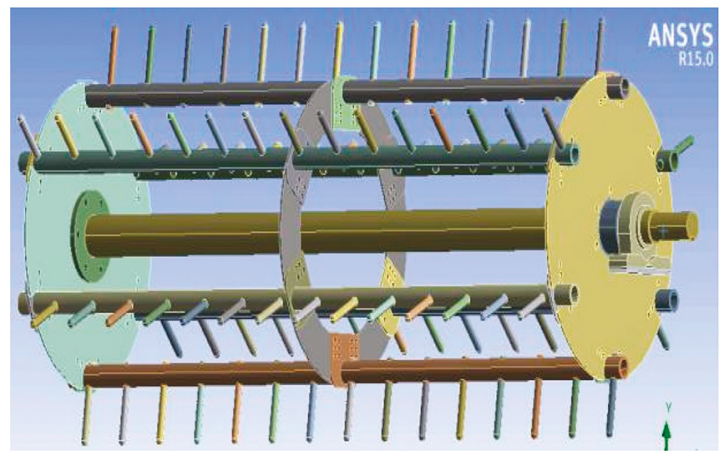

(b)

FIgURE 2: 3D model of cylinder II. (a) Finite element model. (b) Imported model.

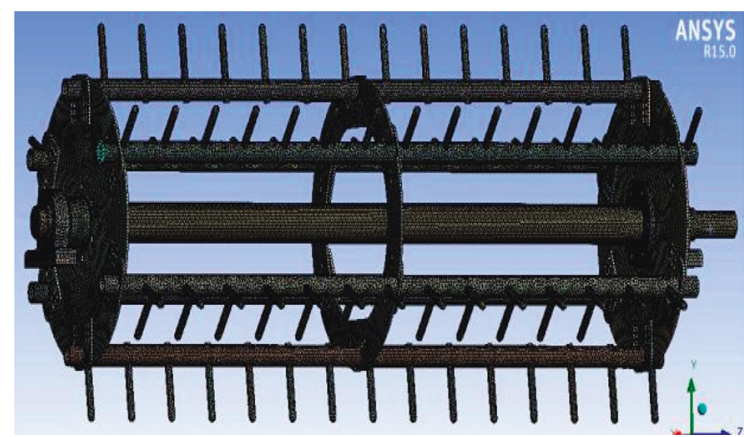

(a)

FIgURE 3: Preprocessing of finite element simulation.

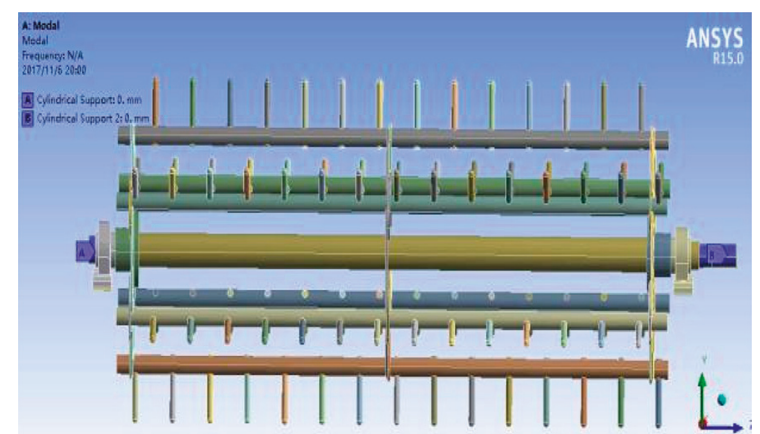

(b)

(a) Mesh model. (b) Restricted modality by bearing.

the excitation had strong influence on the vibration mode and stability of the shaft system [24]. In order to study the variation characteristics law of the axial threshing cylinder during the threshing process, the vibration response of three axial threshing cylinders was analyzed at the rated speed.

2.3.1. Axis Trajectory Test. Eddy current sensors are widely used in large-scale rotating mechanical shaft vibration and axial trajectory testing. Compared with the contact measurements, they have wide measuring range and strong antiinterference ability. Eddy current sensors can collect various parameters of vibration more accurately. The eddy current sensor used for the axis trajectory test of the axial threshing cylinder is shown in Figure 4(a).

The eddy current sensor was produced by Chinese Donghua testing company (5E106 eddy current sensor). It mainly consists of a magnetic probe, an extension cable, and a preamble. The performance index and technical parameters of 5E106 eddy current sensor are shown in Table 1.

Two eddy current sensors were arranged perpendicular to each other at the axial end of cylinder II by using a magnetic base. Two sensors were used to measure the horizontal and vertical displacements of cylinder II. By synthesizing the signals measured by using the sensors, the axis trajectory curve could be obtained. Figure 4(b) shows the axial trajectory test site of cylinder II.
2.3.2. Analysis of Speed Fluctuation. The photoelectric sensor was produced by Chinese Donghua testing company (DH5640 photoelectric sensor). The reflective label was attached to the transmission shaft of the axial threshing cylinder. The laser tube was directed to the reflective label to emit laser light. Then, the reflective label returned part of scattered light to the sensor receiver and became a pulse output through the internal processing circuit. The performance index and technical parameters of the DH5640 photoelectric sensor are shown in Table 2.

2.4. Vibration Test of Bearing Housing. The DHDAS dynamic signal analysis system, DH5902 signal acquisition instrument, signal generator, computer, and 356A16 threecomponent acceleration sensor were used to test the vibration of the bearing housings. The DH5902 signal acquisition instrument is shown in Figure 5.

The modal test equipment component is shown in Table 3.

\section{Results and Discussion}

3.1. Finite Element Analysis of Axial Threshing Cylinder. The mode shapes under the no-load state were solved by ANSYS Workbench, which are shown in Figure 6.

The mode characteristics and frequencies of the first eight modes of cylinder II are shown in Table 4. The $x$ 


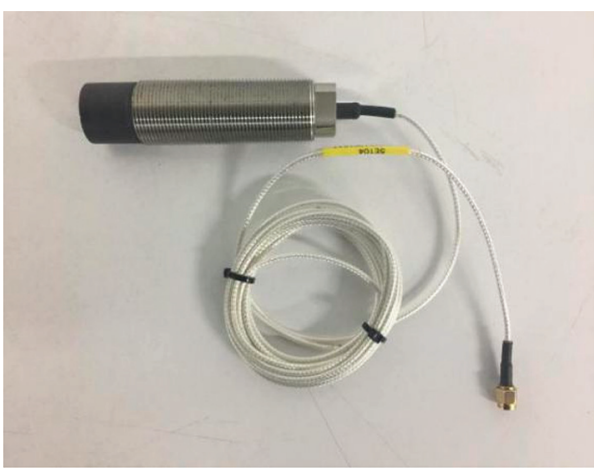

(a)

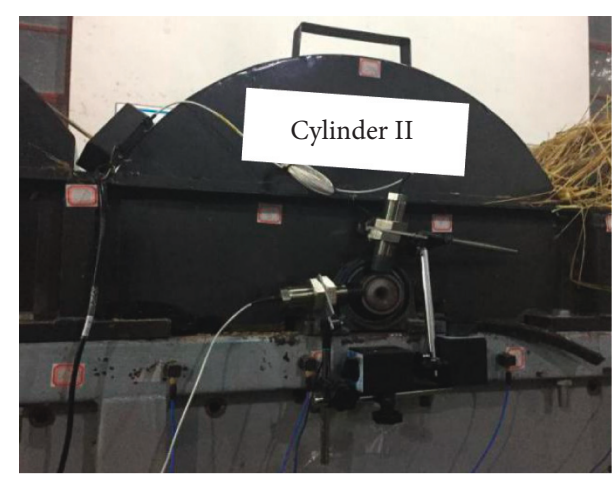

(b)

FIgURe 4: Axis center trajectory test of cylinder II. (a) Eddy current sensor. (b) Test site.

TABle 1: Performance index and parameter of the 5E106 eddy current sensor.

\begin{tabular}{lcccc}
\hline Instrument & Performance index & Parameter & Performance index & Parameter \\
\hline & Sensitivity $(\mathrm{V} / \mathrm{mm})$ & 1 & Minimum measured surface $(\mathrm{mm})$ & $\Phi 58$ \\
$5 \mathrm{~F} 106$ eddy current sensor & Nonlinear error $(\%)$ & \pm 1 & Frequency range $(\mathrm{Hz})$ & $0-10000$ \\
& Range $(\mathrm{mm})$ & 10 & Excitation voltage $(\mathrm{Vdc})$ & $\pm 15 \quad$ \\
& Probe diameter $(\mathrm{mm})$ & $\varphi 25$ & Working temperature $\left({ }^{\circ} \mathrm{C}\right)$ & $-20-120$ \\
\hline
\end{tabular}

TABLE 2: Performance index and parameter of the DH5640 photoelectric sensor.

\begin{tabular}{lcccc}
\hline Instrument & Performance index & Parameter & Performance index & Parameter \\
\hline & Service voltage $(\mathrm{Vdc})$ & 5 & Excitation voltage $(\mathrm{Vdc})$ & $0.3 \mathrm{Vcc}$ \\
$\mathrm{DH} 5640$ photoelectric sensor & Working current $(\mathrm{mA})$ & 50 & Intensity of illumination $(\mathrm{LUX})$ & $<100$ \\
& Range $(\mathrm{rpm})$ & 20000 & Size $(\mathrm{mm}) \quad$ & $\varphi 21 \times 94$ \\
& Monitoring distance $(\mathrm{mm})$ & 70 & Working temperature $\left({ }^{\circ} \mathrm{C}\right)$ & $-10-60$ \\
\hline
\end{tabular}

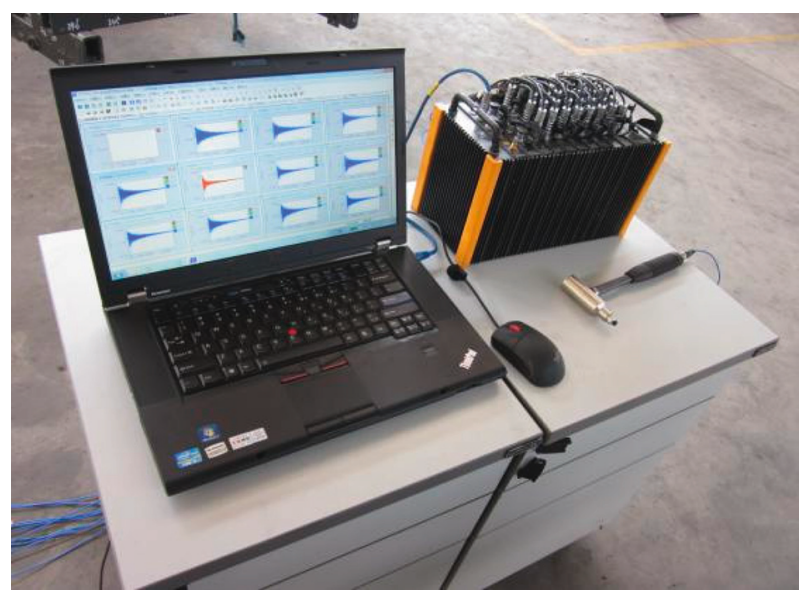

Figure 5: DH5902 dynamic signal acquisition instrument.

direction represented the front and back directions, and the increasing direction represented the back direction. The $y$ direction represented the up and down directions, and the increasing direction represented the up direction. The $z$ direction represented the left and right directions, and the increasing direction represented the right direction.

Modality had infinite orders. Since the low-order vibration had a great influence on the structure of cylinder
TABLE 3: List of the modal test equipment component.

\begin{tabular}{|c|c|c|c|}
\hline No. & Instrument & Instrument no. & Quantity \\
\hline 1 & Signal acquisition instrument & DH5902 & 1 \\
\hline 2 & $\begin{array}{c}\text { Three-component acceleration } \\
\text { sensor }\end{array}$ & $356 A 16$ & 4 \\
\hline 3 & Dynamic signal analysis system & DHDAS 6.10 & 1 \\
\hline 4 & Connecting line & 1 & 13 \\
\hline 5 & Signal generator & 1 & 1 \\
\hline 6 & Computer & ThinkPad & 1 \\
\hline
\end{tabular}

II, only the first 8 modes of cylinder II were taken for analysis. Tang et al. solved the restricted and working modalities of the tangential threshing cylinder by ANSYS software [25]. Some of the mode characteristics of the axial threshing cylinder were similar to those of the tangential threshing cylinder. Because the structures of cylinder II and the tangential threshing cylinder were similar, the results obtained by finite element analysis had certain credibility.

It can be seen from Table 4 and Figure 6 that the natural frequencies of the $1-8$ th modes were below $160 \mathrm{~Hz}$. The 2 nd order and 3rd order modes were local modes of the middle wheel, and the other modes were all holistic modes. When the external excitation frequency is in the range of $50-75 \mathrm{~Hz}$, the middle wheel may become the local weak point. The rated speed of cylinder II was lower than $1000 \mathrm{rpm}$. The 


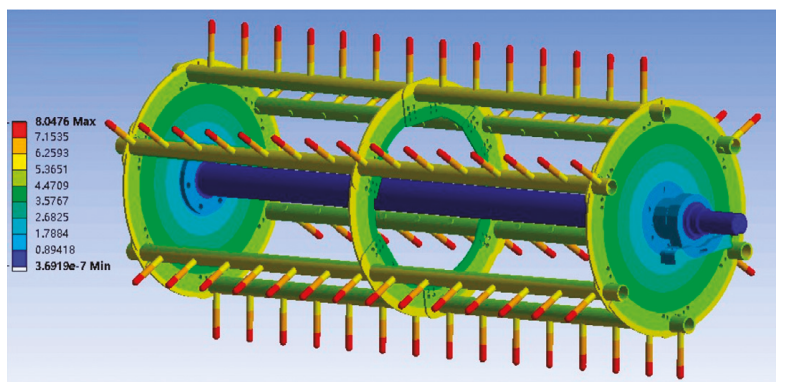

(a)

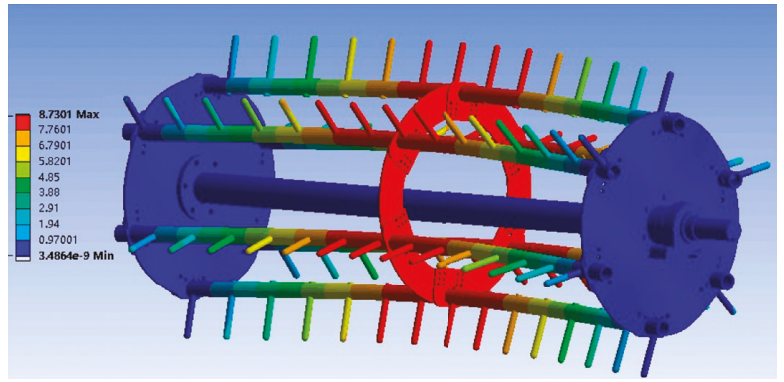

(c)

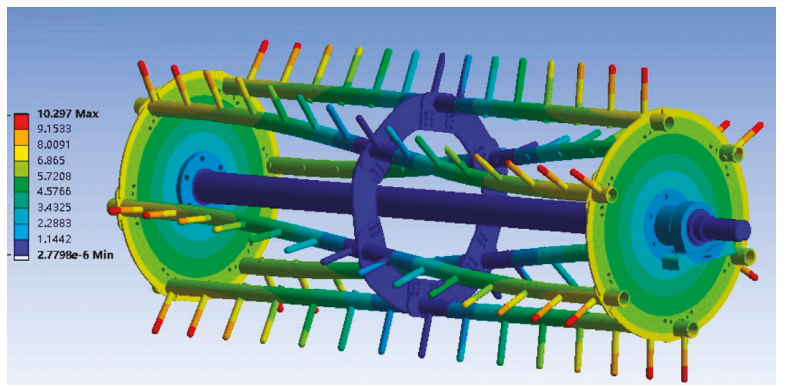

(e)

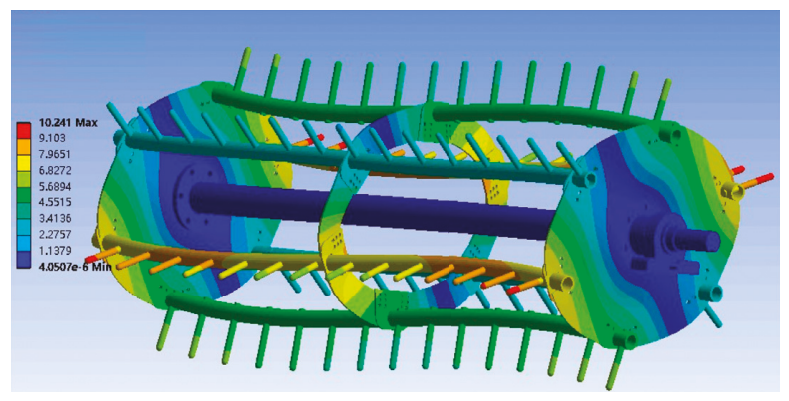

(g)

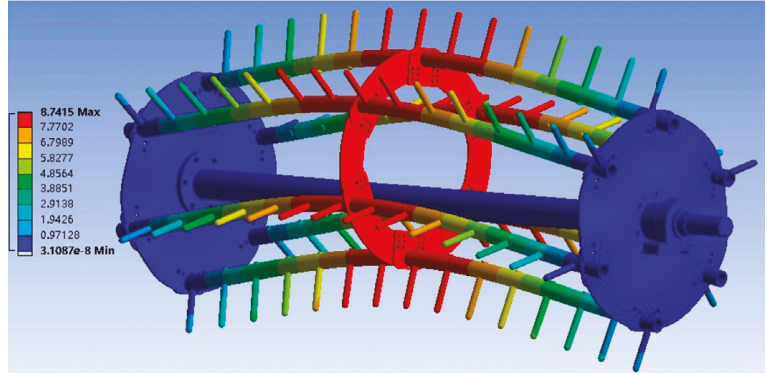

(b)

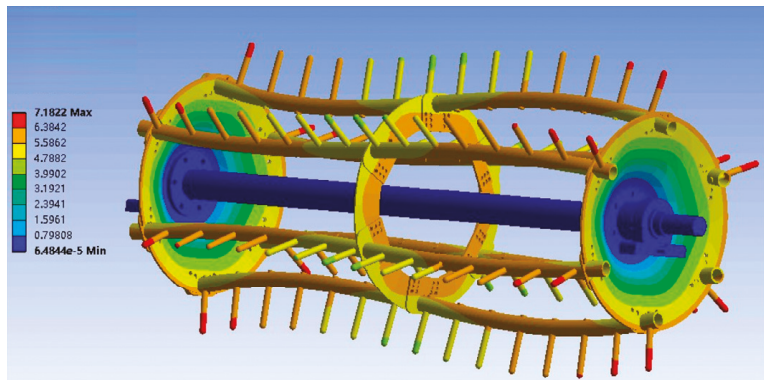

(d)

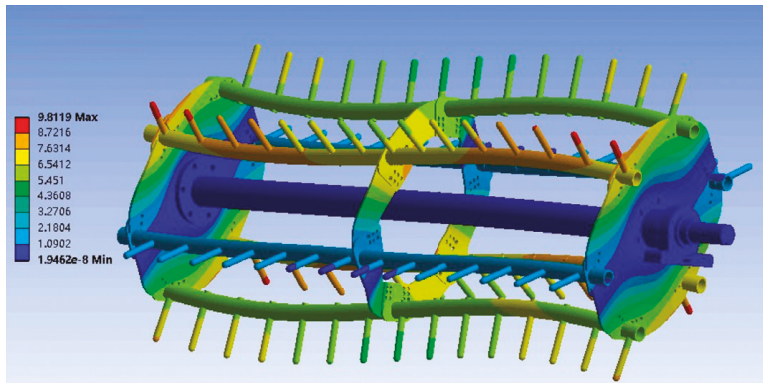

(f)

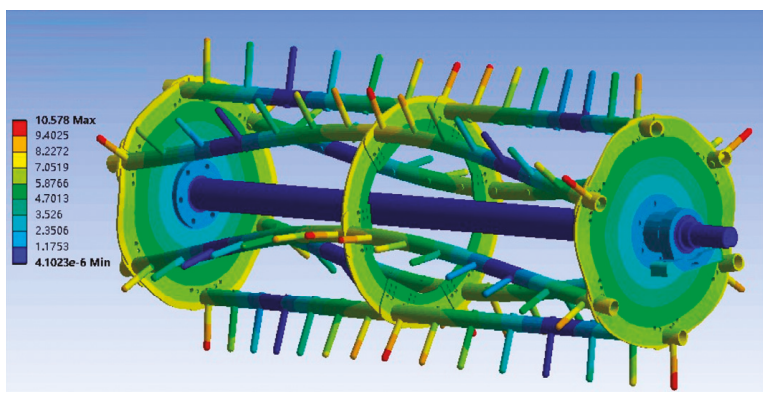

(h)

FiguRE 6: Vibration mode shapes under the no-load state. (a) 1st order mode. (b) 2nd order mode. (c) 3rd order mode. (d) 4th order mode. (e) 5 th order mode. (f) 6 th order mode. (g) 7 th order mode. (h) 8 th order mode.

range of $13.36-20.04 \mathrm{~Hz}$ should be avoided for the natural frequencies of cylinder II from the perspective of avoiding resonance. The 1st order natural frequency of cylinder II was $20.288 \mathrm{~Hz}$, which conformed to the standard and cannot cause the resonance.

Due to the external influences caused by the modal changes, Chen et al. studied the modal of the axial-flow pump rotor system in water and the impact of water on the modal to avoid resonance [26]. The axial threshing cylinder would be entangled by rice under the threshing state.
So the modal of the axial threshing cylinder probably changed and caused the resonance. Using the same method to simulate the modality of cylinder II in the state of containing rice, the results were similar to the modality under no-load state.

The significance of mode analysis is to understand the resonant region of the structure and provide guidance for structural design. It is the basis for other dynamics characteristic analysis. It can provide a basis for the structural design of vibration characteristics, vibration fault 
TABle 4: Mode characteristics and frequencies of cylinder II.

\begin{tabular}{|c|c|c|}
\hline Order & Frequency $(\mathrm{Hz})$ & Mode characteristic \\
\hline 1 & 20.288 & $\begin{array}{c}\text { The cylinder rotated clockwise and counterclockwise cyclically around } \\
\text { the transmission shaft in a range of about } 90^{\circ}\end{array}$ \\
\hline 2 & 62.916 & The middle wheel vibrated along the $y$ direction cyclically \\
\hline 3 & 62.922 & The middle wheel vibrated along the $x$ direction cyclically \\
\hline 4 & 103.03 & The cylinder vibrated along the $z$ direction cyclically, and the bars vibrated like a wave \\
\hline 5 & 122.01 & $\begin{array}{c}\text { The wheel on both sides rotated around the transmission shaft in opposite directions } \\
\text { and caused the bars connected to them to tilt }\end{array}$ \\
\hline 6 & 125.99 & $\begin{array}{l}\text { The cylinder vibrated along the angular bisector of the angle between the increasing } \\
\qquad x \text { direction and the increasing } y \text { direction cyclically }\end{array}$ \\
\hline 7 & 126.04 & $\begin{array}{l}\text { The cylinder vibrated along the angular bisector of the angle between the decreasing } \\
\qquad x \text { direction and the increasing } y \text { direction cyclically }\end{array}$ \\
\hline 8 & 151.36 & $\begin{array}{l}\text { The middle wheel and the wheel on both sides did torsional vibration around the } \\
\text { transmission shaft in the opposite direction }\end{array}$ \\
\hline
\end{tabular}

diagnosis, and optimization design of structural dynamic characteristics.

\subsection{Analysis of Threshing Vibration Response of Axial Threshing Cylinder}

3.2.1. Axis Trajectory Test. Chen et al. found that the spindle vibration largely influenced the stability of the ultraprecision turning machine [27]. Khoshdarregi et al. proposed a feedforward trajectory command shaping algorithm to avoid structural vibrations in the CNC machine [28]. As a high-speed rotating component, cylinder II axis also had dynamic and multidirection vibrations. The axis trajectory of cylinder II under no-load state is shown in Figure 7(a). The maximum displacement, minimum displacement, average displacement, and standard deviation in the horizontal direction were $0.422 \mathrm{~mm},-0.194 \mathrm{~mm}, 0.155 \mathrm{~mm}$, and 0.114 , respectively. The maximum displacement, minimum displacement, average displacement, and standard deviation in the vertical direction were $0.273 \mathrm{~mm}$, $-0.297 \mathrm{~mm},-0.047 \mathrm{~mm}$, and 0.133 , respectively.

The axis trajectory of cylinder II under the threshing state is shown in Figure 7(b). The maximum displacement, minimum displacement, average displacement, and standard deviation in the horizontal direction were $0.401 \mathrm{~mm}$, $-0.581 \mathrm{~mm},-0.093 \mathrm{~mm}$, and 0.221 , respectively. The maximum displacement, minimum displacement, average displacement, and standard deviation in the vertical direction were $0.421 \mathrm{~mm},-0.846 \mathrm{~mm},-0.223 \mathrm{~mm}$, and 0.237 , respectively. Compared with the no-load state, the horizontal amplitude of cylinder II increased by $0.366 \mathrm{~mm}$. The average value of the displacement moved $0.248 \mathrm{~mm}$ to the negative direction. The vertical amplitude increased by $0.697 \mathrm{~mm}$, and the average value of the displacement moved $0.176 \mathrm{~mm}$ to the negative direction. Saito et al. predicted the nonlinear forced vibration response of a turbine engine rotor with a cracked blade [29]. The results showed that the cracked blade could cause an imbalance of the system. There were the same conclusions in this paper. It indicated that rice load could affect the balance of cylinder II and intensify the vibration under threshing state. The main range of vibration would shift.
The axial trajectory in Figure 7 covered with each other due to the long test time. The amplitude and distribution range of the axis trajectory could only be observed as a whole. It is necessary to reduce the number of curves to explore the pulsation law of the axis trajectory. As shown in Figure 8 , the time interval of the test data was shortened to $0.1 \mathrm{~s}$.

As shown in Figure 8(a), the axis trajectory of cylinder II under no-load state was disordered. The amplitude of each rotation was greatly different, and the distribution range of the curve was relatively dispersed. The axis trajectory of cylinder II under the threshing state is shown in Figure $8(\mathrm{~b})$. Although the amplitude was increased compared to the amplitude under no-load state, the distribution range was concentrated. The directions and amplitudes of the vibration generated by each rotation were substantially the same.

3.2.2. Analysis of Speed Fluctuation. The speed fluctuation curves of cylinder II under no-load state and threshing state are shown in Figures 9(a) and 9(b), respectively.

The speed of cylinder II fluctuated around $763 \mathrm{rpm}$ under no-load state. The fluctuation range was between 761 and $765 \mathrm{rpm}$. Tang et al. have tested the torque and speed of the axial threshing cylinder. They found that the speed would show a minor fluctuation due to the fluctuation of the input power [30]. So the measured fluctuation range of speed under no-load state was normal. When cylinder II was under threshing state, the speed of cylinder II fluctuated around $750 \mathrm{rpm}$. And the fluctuation range was between 744 and $754 \mathrm{rpm}$. When the input power was constant, the speed of cylinder II under threshing state was lower than it under noload state. But the fluctuation range increased. It showed that threshing process affected the speed and stability of the axial threshing cylinder. The rice twined around the axial cylinder and increased the load of cylinder II. So the speed decreased under threshing state. Because the rice twined around the cylinder unevenly, the stability of the axial threshing cylinder was destroyed.

Cylinder II generated excitation frequency when it rotated. If the excitation frequency was close to the natural frequencies, cylinder II would resonate. The excitation 


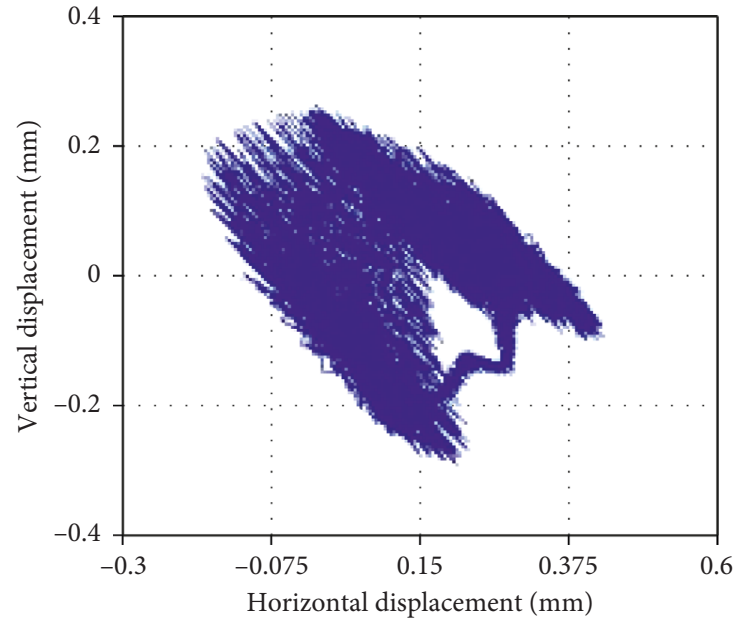

(a)

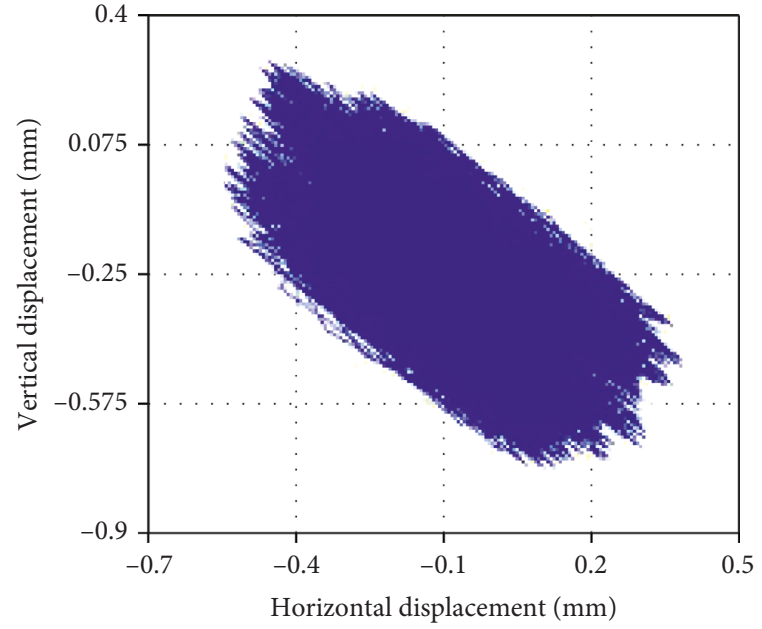

(b)

FIGURE 7: Axis trajectory of cylinder II. (a) Under no-load condition. (b) Under threshing condition.

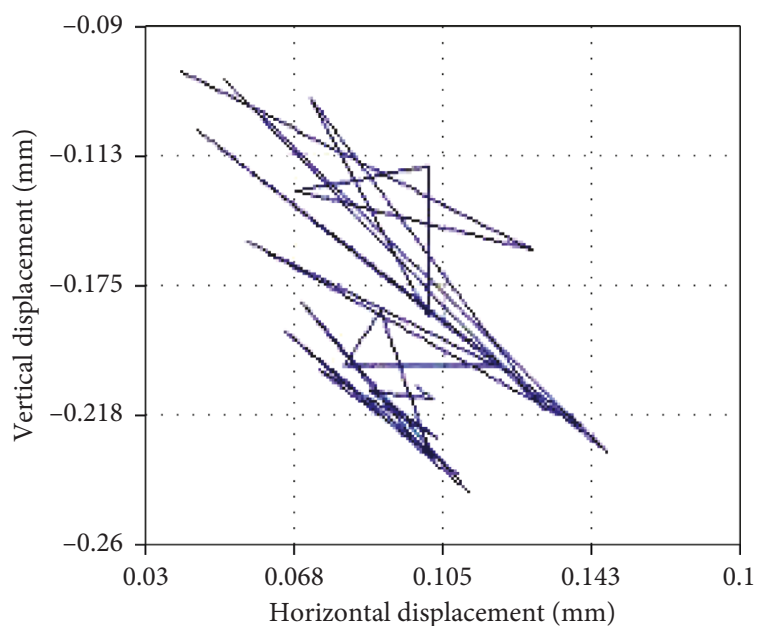

(a)

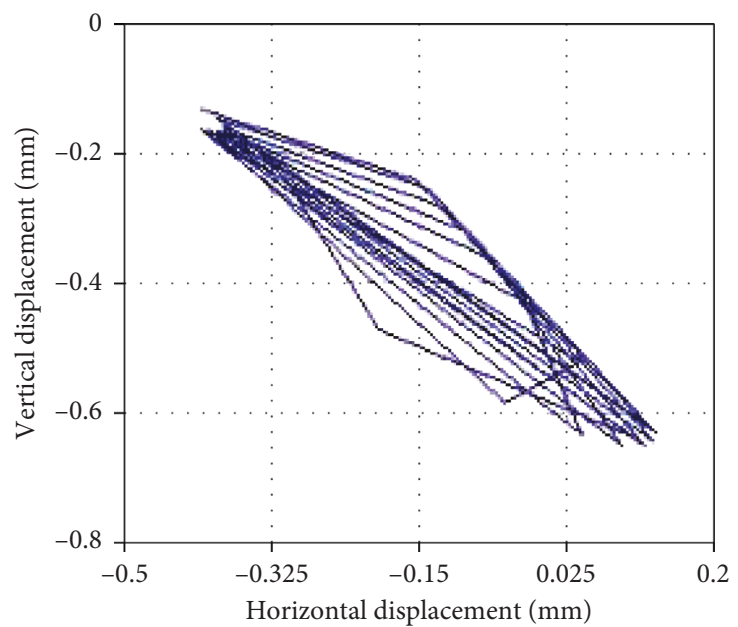

(b)

FIGURE 8: Axis trajectory of cylinder II in 0.1 second. (a) Under no-load condition. (b) Under threshing condition.

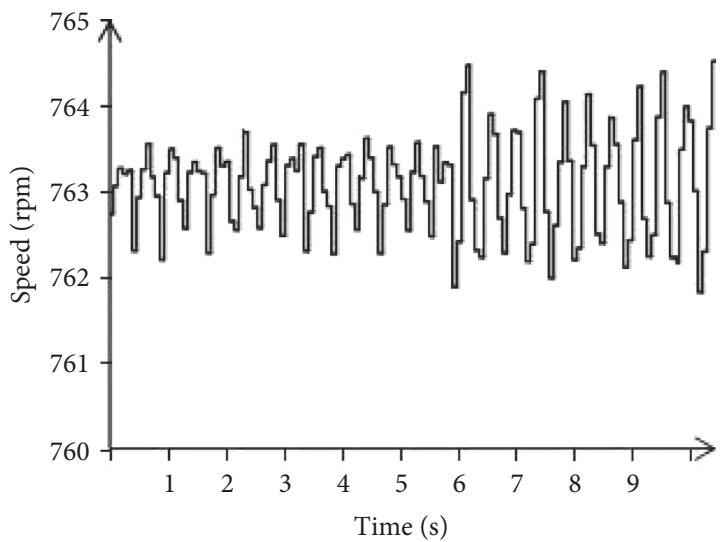

(a)

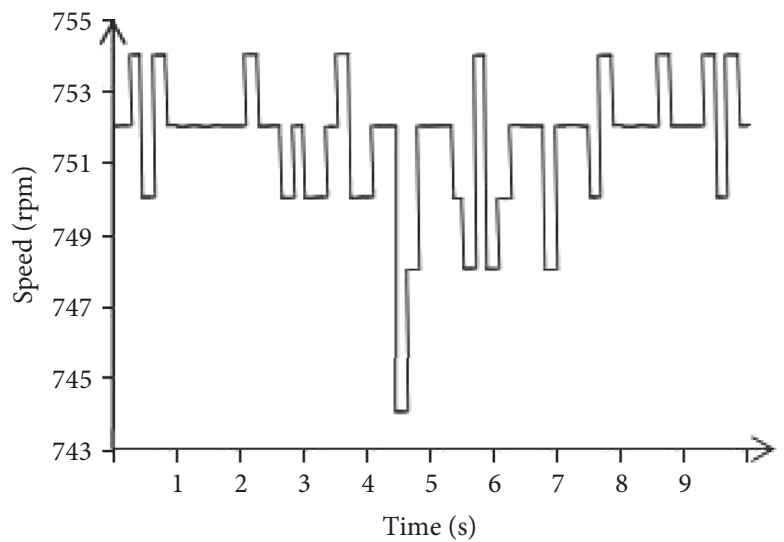

(b)

FIGURE 9: Speed fluctuation curve of cylinder II. (a) Under no-load condition. (b) Under threshing condition. 
frequency under no-load state was about $12.72 \mathrm{~Hz}$. The excitation frequency reduced to about $12.5 \mathrm{~Hz}$ under threshing state due to the decrease in the speed. Because the mode frequency increased with the increase of the order, the excitation frequency was most likely to resonate with the 1st mode frequency. The 1st theoretical mode of cylinder II was $20.288 \mathrm{~Hz}$, and the resonance interval was $16.23 \mathrm{~Hz}-$ $24.35 \mathrm{~Hz}$. The 1st experimental mode of cylinder II was $46.209 \mathrm{~Hz}$, and the resonance interval was $36.97 \mathrm{~Hz}-$ $55.45 \mathrm{~Hz}$. The excitation frequency was obviously not in the resonance intervals, so the excitation frequency of cylinder II could not cause its own resonance phenomenon under noload state and threshing state, so the speed fluctuation of cylinder II was not caused by the resonance phenomenon.

\subsection{Analysis of Vibration Coupling Characteristics of Co-Frame} Multicylinder. Cao et al. analyzed the vibration characteristics of a cylindrical shell-circular plate coupled structure subjected to various boundary conditions. The effects of several significant factors, including the restraint stiffness, the coupling stiffness, and the situation of coupling, were presented [31]. As a cylindrical object, the single axial threshing cylinder system also had the similar vibration characteristics similar to those of the cylindrical shellcircular plate-coupled structure. Compared to the single axial threshing cylinder system, the vibration characteristics of the co-frame multiroller system were no longer independent. The vibration of axial threshing cylinders would be coupled and interacted through the frame. In order to study the mutual influence among the vibration of the axial threshing cylinders, the axial trajectory and the vibration of the bearing housing were measured under the condition that the axial threshing cylinders were jointly opened. Then the condition of resonance between the cylinders was analyzed, which provided ideas and basis for the research work of multicylinder coupled vibration.

3.3.1. Axial Vibration Test. Brazinskas et al. measured the rotor-to-rotor interference at the static state in various overlapping propulsion system configurations. They found that the interference would affect the rotor performance [32]. The axial threshing cylinders could also be considered as rotors. Cylinder II rotated at a constant speed of $760 \mathrm{rpm}$, and the running state of cylinder I and cylinder III was adjusted. Then the axial vibration of cylinder II was measured. Table 5 compares the axial vibration of cylinder II under different conditions.

As shown in Table 5, cylinder III was closed and the speed of cylinder I was gradually increased from $600 \mathrm{rpm}$ to $1000 \mathrm{rpm}$. The standard deviation of the horizontal amplitude of cylinder II fluctuated within the interval of 0.1050.107 . The standard deviation of the vertical amplitude of cylinder II fluctuated within the interval of 0.089-0.092. There was no linear relationship between the standard deviation and the speed of cylinder I. It is indicated that the change in the speed of cylinder I cannot cause significant changes to cylinder II.
When cylinder I and cylinder II were under constant running state, cylinder III was opened and the rotation speed was almost the same as cylinder I. The standard deviation of the horizontal amplitude of cylinder II fluctuated within the interval of $0.214-0.242$, which was twice that before the opening of cylinder III. The standard deviation of the vertical amplitude of cylinder II fluctuated within the interval of 0.214-0.222, which was 2.5 times that before the opening of cylinder III. After cylinder III was opened, the standard deviation did not increase with the increase of the speed of cylinder I and cylinder III. It is indicated that the operation of cylinder III can affect the stability of cylinder II. The increase of cylinder III's speed cannot intensify the instability of cylinder II.

When cylinder II ran at $760 \mathrm{rpm}$, the speeds of cylinder I and cylinder III were adjusted synchronously. The axial amplitude of cylinder II is shown in Figure 10.

As can be seen from Figure 10(a), the horizontal amplitude of cylinder II was substantially unaffected by the change of the speeds of cylinder I and cylinder III. When cylinder I and cylinder II were opened and cylinder III was closed, the horizontal amplitude of cylinder II was always about $0.6 \mathrm{~mm}$. It did not increase with the increase of cylinder I's speed. When cylinder I, cylinder II, and cylinder III were simultaneously opened, the horizontal amplitude of cylinder II increased to about $1.2 \mathrm{~mm}$. It had no tendency to increase with the increase of the speeds of cylinder I and cylinder III.

As shown in Figure 10(b), the vertical amplitude of cylinder II was substantially unaffected by the speeds change of cylinder I and cylinder III. When cylinder I and cylinder II were opened and cylinder III was closed, the vertical amplitude of cylinder II always fluctuated between $0.5 \mathrm{~mm}$ and $0.6 \mathrm{~mm}$. It did not increase with the increase of cylinder I's speed. When cylinder I, cylinder II, and cylinder III were simultaneously opened, the vertical amplitude of cylinder II increased to $0.95-1.1 \mathrm{~mm}$. It had no tendency to increase with the increase in the speeds of cylinder I and cylinder III. The above results showed that the vibration between the axial threshing cylinders would interfere with each other, but there was no linear relationship between the intensity of the interference and the speed of the axial threshing cylinders.

3.3.2. Vibration Test of Bearing Housing. According to the finite element method, Shamim and Berezhnoi explained the interference influence of rotor nozzle centrifugal compressor on the shaft [33]. This type of interference also existed on the axial threshing cylinders. In order to explore the influence of the interference on the axial threshing cylinder performance, this paper took the co-frame multicylinder test bench as the subject to investigate. In the case of single axial threshing and double axial threshing cylinders rotating together, the vibration signals at the bearing housing were collected by using the 356A16 three-way acceleration sensors. The interaction between the vibrations of the cylinders was compared and analyzed.

The time-vertical displacement curve at the bearing housing of cylinder II is shown in Figure 11. The blue 
TABLE 5: Axis vibration of cylinder II under different conditions.

\begin{tabular}{|c|c|c|c|c|c|c|c|c|}
\hline \multicolumn{3}{|c|}{ Rotating speed (rpm) } & \multicolumn{6}{|c|}{ Axis vibration amplitude of cylinder II } \\
\hline \multirow[b]{2}{*}{$\begin{array}{l}\text { Cylinder } \\
\text { I }\end{array}$} & \multirow[b]{2}{*}{$\begin{array}{c}\text { Cylinder } \\
\text { II }\end{array}$} & \multirow{2}{*}{$\begin{array}{c}\text { Cylinder } \\
\text { III }\end{array}$} & \multicolumn{3}{|c|}{ Horizontal direction } & \multicolumn{3}{|c|}{ Vertical direction } \\
\hline & & & $\begin{array}{l}\text { Maximum } \\
(\mathrm{mm})\end{array}$ & $\begin{array}{l}\text { Minimum } \\
(\mathrm{mm})\end{array}$ & $\begin{array}{l}\text { Standard } \\
\text { deviation }\end{array}$ & $\begin{array}{l}\text { Maximum } \\
(\mathrm{mm})\end{array}$ & $\begin{array}{l}\text { Minimum } \\
(\mathrm{mm})\end{array}$ & $\begin{array}{l}\text { Standard } \\
\text { deviation }\end{array}$ \\
\hline 600 & 760 & l & 0.246 & -0.288 & 0.105 & 0.077 & -0.428 & 0.091 \\
\hline 600 & 760 & 600 & 0.772 & -0.477 & 0.242 & 0.129 & -0.843 & 0.214 \\
\hline 700 & 760 & 1 & 0.283 & -0.286 & 0.107 & 0.219 & -0.289 & 0.09 \\
\hline 700 & 760 & 700 & 0.694 & -0.438 & 0.214 & 0.469 & -0.586 & 0.222 \\
\hline 800 & 760 & l & 0.209 & -0.312 & 0.105 & 0.066 & -0.432 & 0.089 \\
\hline 800 & 760 & 800 & 0.376 & -0.873 & 0.224 & 0.353 & -0.697 & 0.225 \\
\hline 900 & 760 & I & 0.242 & -0.322 & 0.104 & 0.277 & -0.275 & 0.09 \\
\hline 900 & 760 & 900 & 0.451 & -0.784 & 0.234 & 0.189 & -0.854 & 0.214 \\
\hline 1000 & 760 & 1 & 0.246 & -0.315 & 0.106 & 0.088 & -0.438 & 0.092 \\
\hline 1000 & 760 & 1000 & 0.242 & -1.043 & 0.237 & 0.637 & -0.444 & 0.217 \\
\hline
\end{tabular}

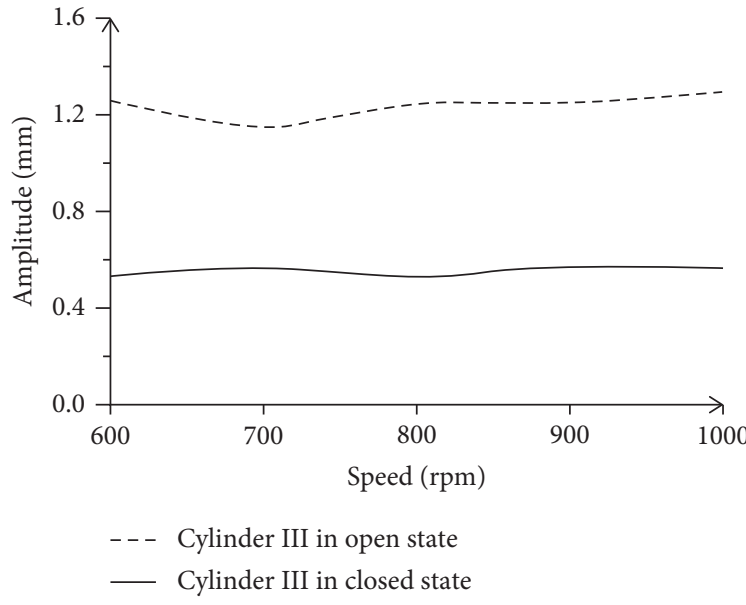

(a)

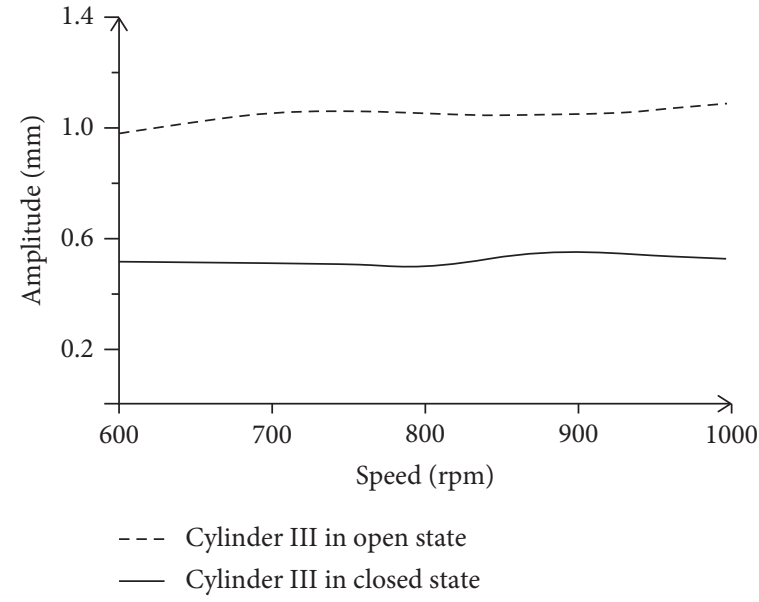

(b)

Figure 10: Axial amplitude of cylinder II under different conditions. (a) Horizontal amplitude. (b) Vertical amplitude.

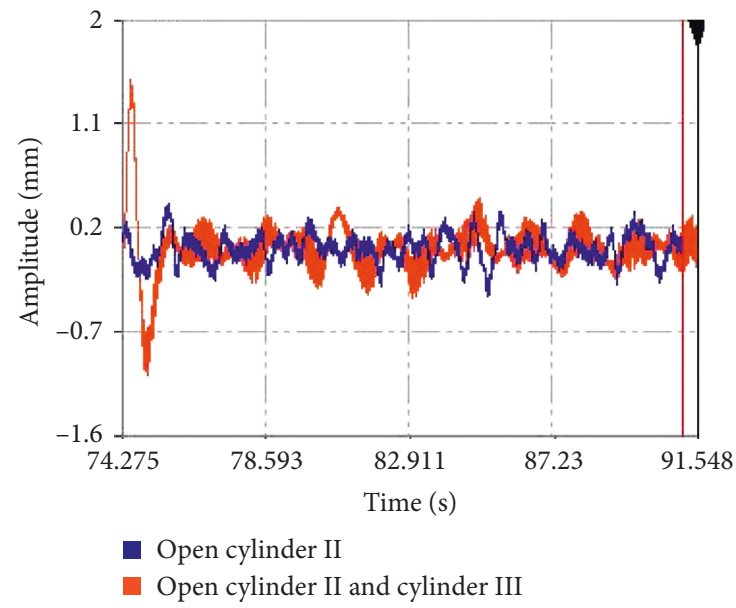

(a)

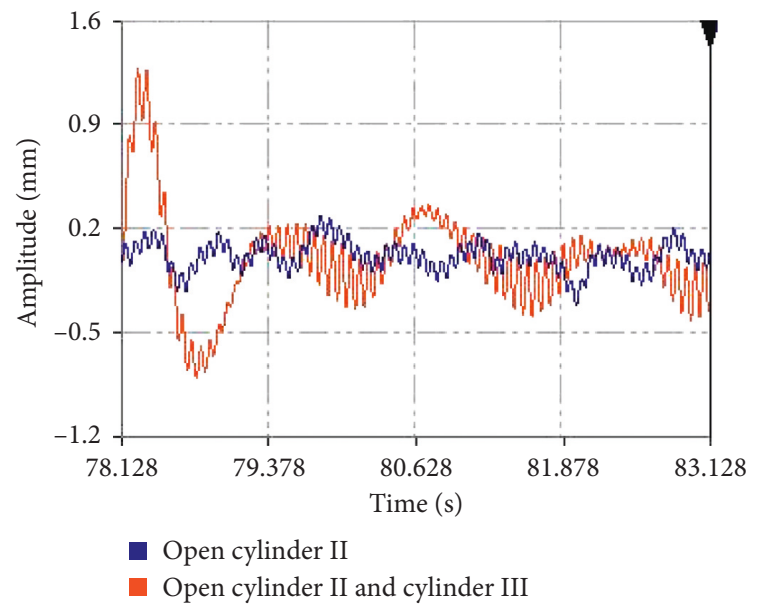

(b)

FIgURE 11: Vertical displacement of the bearing housing of cylinder II. (a) Time-vertical displacement curve. (b) Enlarged drawing. 
curve represented the state in which cylinder II operated alone. The orange curve represented the state in which cylinder II and cylinder III were in motion at the same time. Cylinder II and cylinder III ran at the rated speed.

As shown in Figure 11(a), in the case where cylinder II and cylinder III operated simultaneously, the vertical vibration at the bearing housing of cylinder II was more severe. As shown in Figure 11(b), the time-vertical displacement curves were partially enlarged. The blue curve was a mixed waveform of low frequency and high frequency. The orange curve increased the characteristics of the beat wave. It is indicated that the vibration of cylinder III transmitted through the frame to the bearing housing of cylinder II, and a superposition was produced.

Table 6 shows the vertical displacement and standard deviation of the bearing housing of cylinder II.

As can be seen from Table 6, when cylinder II and cylinder III were operated simultaneously, the amplitude at the bearing housing of cylinder II was increased from $0.661 \mathrm{~mm}$ to $0.747 \mathrm{~mm}$. The standard deviation was increased from 0.097 to 0.131 . It shows that the operation of cylinder III intensifies the vibration at the bearing housing of cylinder II.

Figure 12(a) shows the time-vertical displacement curve of the bearing housing of cylinder II under different conditions in $1 \mathrm{~s}$. The spectrum diagram in the interval where the amplitude of the orange curve is significantly larger than that of the blue curve is shown in Figure 12(b). As can be seen from Figure 12(a), the curves had 13 complete vibration waveforms in $1 \mathrm{~s}$. The quantity was basically consistent with the excitation frequency of cylinder II. It can be seen from Figure 12(b) that the energy of the high-frequency interval was strong when cylinder II operated alone. The energy at $13.672 \mathrm{~Hz}$ enhanced significantly when cylinder II and cylinder III operated simultaneously. The frequency was basically consistent with the number of waveforms. The operation of cylinder III intensified the vertical vibration at the bearing housing of cylinder II.

The time-vertical displacement curve at the bearing housing of the cylinder III is shown in Figure 13. The blue curve represented the state in which cylinder III operated alone. The orange curve represented the state in which cylinder II and cylinder III were in motion at the same time. Cylinder II and cylinder III ran at the rated speed.

As can be seen from Figure 13(a), in the case where cylinder II and cylinder III operated simultaneously, the vertical vibration at the bearing housing of cylinder III was more severe. As shown in Figure 13(b), the timevertical displacement curves were partially enlarged. The blue curve was a mixed waveform of low frequency and high frequency. The orange curve increased the characteristics of the beat wave. It is indicated that the vibration of cylinder II transmitted through the frame to the bearing housing of cylinder III, and a superposition was produced.

The vertical displacement and standard deviation of the bearing housing of cylinder III are shown in Table 7.
TABLE 6: Vertical vibration parameters of the bearing housing of cylinder II.

\begin{tabular}{lcc}
\hline $\begin{array}{l}\text { Measuring point of } \\
\text { running cylinder }\end{array}$ & \multicolumn{2}{c}{ The bearing housing of cylinder II } \\
Cylinder II & Cylinder II and cylinder III \\
\hline $\begin{array}{l}\text { Peak value of forward } \\
\text { displacement (mm) }\end{array}$ & 0.319 & 0.420 \\
$\begin{array}{l}\text { Peak value of negative } \\
\text { displacement (mm) }\end{array}$ & -0.342 & -0.327 \\
\begin{tabular}{l} 
Standard deviation \\
\hline
\end{tabular} & 0.097 & 0.131 \\
\hline
\end{tabular}

As can be seen from Table 7, when cylinder II and cylinder III were operated simultaneously, the amplitude at the bearing housing of cylinder III increased from $0.43 \mathrm{~mm}$ to $0.528 \mathrm{~mm}$. The standard deviation increased from 0.076 to 0.099. It shows that the operation of cylinder II intensifies the vibration at the bearing housing of cylinder III.

Figure 14(a) shows the time-vertical displacement curve of the bearing housing of cylinder III under different conditions in $1 \mathrm{~s}$. The spectrum diagram in the interval where the amplitude of the orange curve is significantly larger than the blue curve is shown in Figure 14(b). As can be seen from Figure 14(a), the curves had 13 complete vibration waveforms in $1 \mathrm{~s}$. The quantity was basically consistent with the excitation frequency of the axial threshing cylinder. It can be seen from Figure 14(b) that the energy at $13.672 \mathrm{~Hz}$ was 0.63 when cylinder III operated alone. When cylinder II and cylinder III operated at the same time, the energy at $13.672 \mathrm{~Hz}$ intensified to 1.01 . The energy at $25.391 \mathrm{~Hz}$ and $39.063 \mathrm{~Hz}$ also enhanced. $25.391 \mathrm{~Hz}$ and $39.063 \mathrm{~Hz}$ were the double and triple frequencies of the rotation speed frequency. The operation of cylinder II intensified the vertical vibration at the bearing housing of cylinder III.

The mutual interference and coupling of vibration between cylinder I and cylinder II were analyzed in the same way. The vertical displacement and standard deviation of the bearing housing of cylinder I and cylinder II are shown in Table 8.

As shown in Table 8, when cylinder I and cylinder II were operated simultaneously, the amplitude at the bearing housing of cylinder I increased from $0.382 \mathrm{~mm}$ to $0.774 \mathrm{~mm}$. The standard deviation increased from 0.054 to 0.133 . The amplitude at the bearing housing of cylinder II increased from $0.409 \mathrm{~mm}$ to $0.709 \mathrm{~mm}$. The standard deviation increased from 0.083 to 0.119 . When cylinder I and cylinder II rotated at the same time, their unbalanced vibration had mutual interference and coupling. It caused the vibration at the bearing housings to be intensified.

Zhang et al. analyzed and studied the beat frequency phenomenon in the vibration fault of asynchronous motor through the steps of test analysis and comprehensive diagnosis [34]. The time-displacement curve in this paper has the same characteristics as those in reference [34]. It confirms the conclusion that there is a beat vibration phenomenon among axial threshing cylinders. The source of the beat vibration is that the vibrations produced by the cylinders transmitted together and superimposed. 


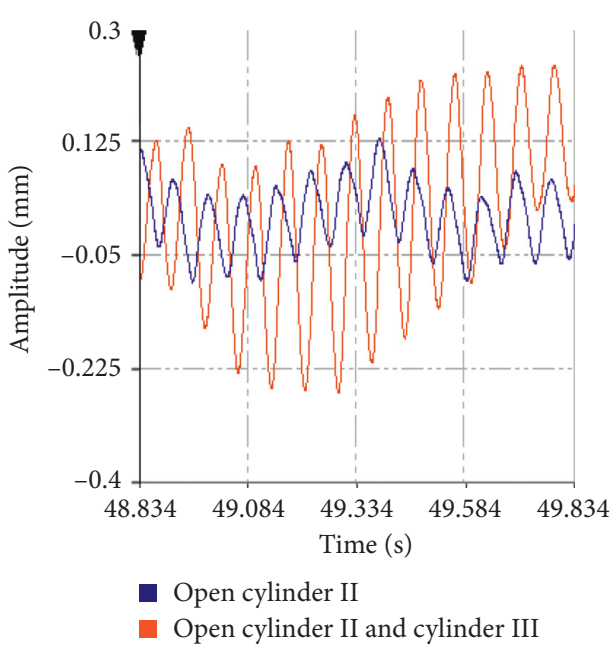

(a)

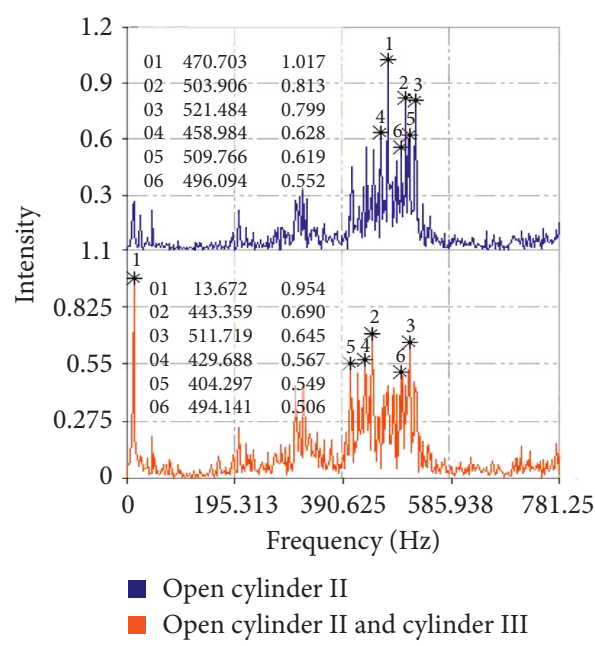

(b)

FIgURE 12: Vertical displacement of the bearing housing of cylinder II in 1 s. (a) Time-vertical displacement curve in 1 s. (b) Time-frequency spectrogram.

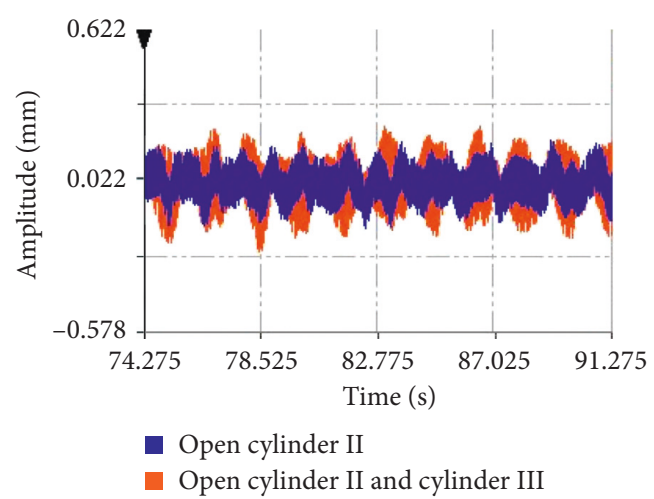

(a)

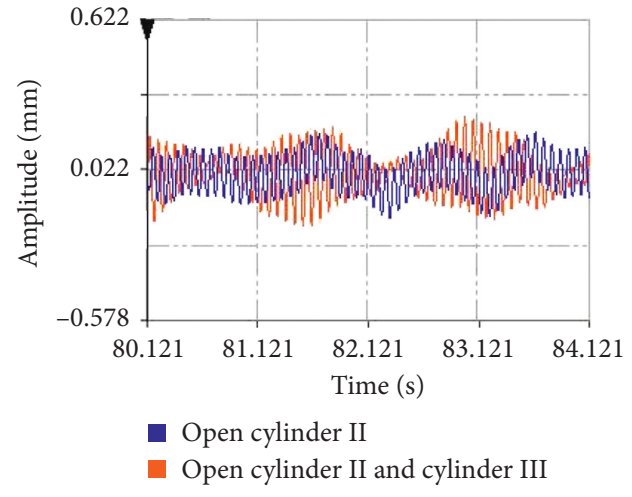

(b)

FIgURe 13: Vertical displacement of the bearing housing of cylinder III. (a) Time-vertical displacement curve. (b) Enlarged drawing.

TABLE 7: Vertical vibration parameters of the bearing housing of cylinder III.

\begin{tabular}{|c|c|c|}
\hline \multirow{2}{*}{$\begin{array}{l}\text { Measuring point of } \\
\text { running cylinder }\end{array}$} & \multicolumn{2}{|c|}{ The bearing housing of cylinder III } \\
\hline & Cylinder III & Cylinder II and cylinder III \\
\hline $\begin{array}{l}\text { Peak value of forward } \\
\text { displacement }(\mathrm{mm})\end{array}$ & 0.227 & 0.247 \\
\hline $\begin{array}{l}\text { Peak value of negative } \\
\text { displacement }(\mathrm{mm})\end{array}$ & -0.203 & -0.281 \\
\hline Standard deviation & 0.076 & 0.099 \\
\hline
\end{tabular}

\section{Conclusion}

The theoretical modes were solved by ANSYS Workbench, which showed that the 1st, $2 \mathrm{nd}$, and $3 \mathrm{rd}$ modal shape frequency were $20.288 \mathrm{~Hz}, 62.916 \mathrm{~Hz}$, and $62.922 \mathrm{~Hz}$, respectively. The 1st, $2 \mathrm{nd}$, and $3 \mathrm{rd}$ modal shape frequencies were higher than the rotational frequency under no-load state $(12.72 \mathrm{~Hz})$ and threshing state $(12.5 \mathrm{~Hz})$. The speed frequencies will not cause the resonance of the axial threshing cylinder. The violent vibration of axial threshing cylinders under threshing state was caused by the vibration coupling and interference.

By comparing the axial trajectories and the rotational speeds of cylinder II under no-load state and threshing state, it was found that the rice would reduce the speed of cylinder II from 761-765 rpm to 744-754 rpm under threshing state. The vibration of the transmission shaft was intensified. The main scope of the vibration was shifted. It showed that threshing process affected the speed and stability of the axial threshing cylinder. The rice twined around the axial threshing cylinder and increased the load of cylinder II. So the speed decreased under threshing state. Because the rice twined around the cylinder unevenly, the stability of the cylinder was destroyed.

When cylinder II worked at the rated speed, the horizontal and vertical amplitudes of the transmission shaft were maintained between 0.5 and $0.6 \mathrm{~mm}$ after cylinder I was opened. When cylinder III was opened, the horizontal amplitude of the transmission shaft increased to about 


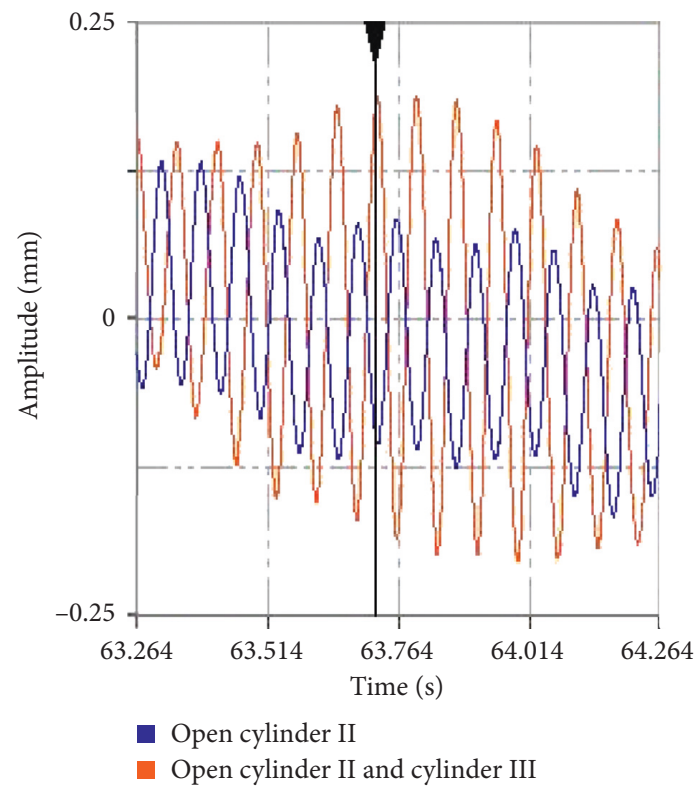

(a)

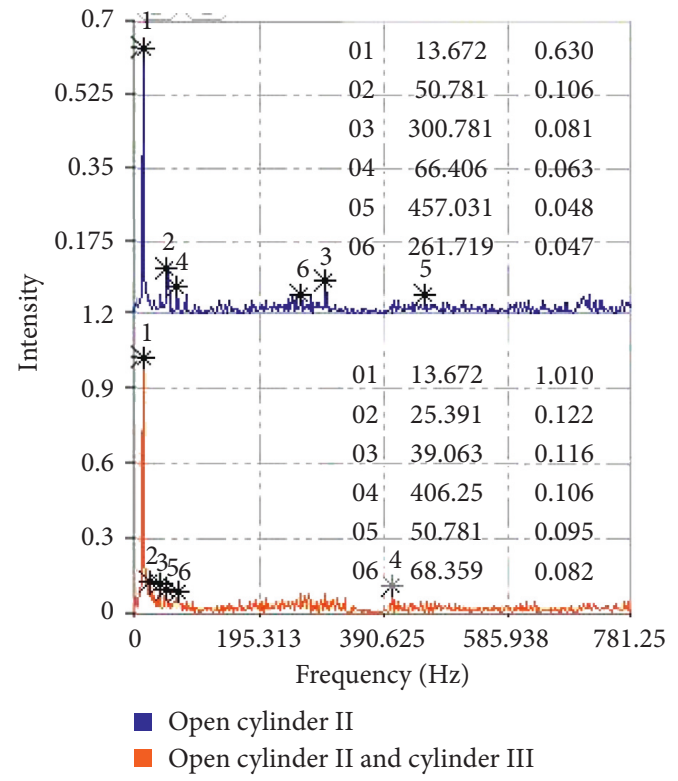

(b)

Figure 14: Vertical displacement of the bearing housing of cylinder III in 1 s. (a) Time-vertical displacement curve in 1 s. (b) Time-frequency spectrogram.

TABLE 8: Vertical vibration parameters of the bearing housing of cylinder I and cylinder II.

\begin{tabular}{lcccc}
\hline \multirow{2}{*}{ Measuring point of running cylinder } & \multicolumn{2}{c}{ The bearing housing of cylinder I } & \multicolumn{2}{c}{ The bearing housing of cylinder II } \\
& Cylinder I & Cylinder I and cylinder II & Cylinder II & Cylinder II and cylinder III \\
\hline Peak value of forward displacement $(\mathrm{mm})$ & 0.215 & 0.426 & 0.225 & 0.355 \\
Peak value of negative displacement $(\mathrm{mm})$ & -0.167 & -0.348 & -0.184 & -0.354 \\
Standard deviation & 0.054 & 0.133 & 0.083 & 0.119 \\
\hline
\end{tabular}

$1.2 \mathrm{~mm}$. The vertical amplitude increased to $0.95-1.1 \mathrm{~mm}$. The operation stability of cylinder II would be affected by the rotation of cylinder I and cylinder III, but there was no linear relationship between the intensity of the interference and the speed of the cylinders.

By comparing the amplitude of the bearing housing, the disturbance and coupling relationships among the unbalanced vibration of cylinders were analyzed. The amplitude and standard deviation of the bearing housing increased due to the operation of adjacent cylinders. Obvious beat signals could be seen from the time-displacement curve. It shows that the unbalanced vibration of the axial threshing cylinder will transmit through the frame and cause mutual disturbance to occur. Owing to the speeds among the axial threshing cylinders are similar, the rotational frequencies of the axial threshing cylinders will cause the beat phenomenon. The unbalanced vibration of threshing cylinders will intensify.

\section{Data Availability}

The data used to support the findings of this study are available from the corresponding author upon request.

\section{Conflicts of Interest}

The authors declare that they have no conflicts of interest.

\section{Acknowledgments}

This research work was supported by the National Natural Science Foundation of China (51705212), Natural Science Foundation of Jiangsu Province (BK20170553), National Key Research and Development Plan (2016YFD0702004), and A Project Funded by the Priority Academic Program Development of Jiangsu Higher Education Institutions (PAPD).

\section{References}

[1] D. Huang, S. Zhou, and G. Litak, "Theoretical analysis of multi-stable energy harvesters with high-order stiffness terms," Communications in Nonlinear Science and Numerical Simulation, vol. 69, no. 1, pp. 270-286, 2019.

[2] Z. P. Gao, L. Z. Xu, Y. M. Li, Y. D. Wang, and P. P. Sun, "Vibration measure and analysis of crawler-type rice and wheat combine harvester in field harvesting condition," Transactions of the Chinese Society of Agricultural Engineering, vol. 33, no. 20, pp. 48-55, 2017.

[3] A. M. Kociolek, A. E. Lang, C. M. Trask, R. M. Vasiljev, and S. Milosavljevic, "Exploring head and neck vibration exposure from quad bike use in agriculture," International Journal of Industrial Ergonomics, vol. 66, pp. 63-69, 2018.

[4] Y. Yao, Y. Du, Z. Zhu, E. Mao, and Z. Song, "Vibration characteristics analysis and optimization of corn combine 
harvester frame using modal analysis method," Transactions of the Chinese Society of Agricultural Engineering, vol. 31, no. 19, pp. 46-53, 2015.

[5] Y. M. Li, L. H. Zhu, Z. Tang, and L. Z. Xu, "Finite element modal analysis and experiment of the compression device of the all-in-one machine of combine harvester and baler," AER-Advances in Engineering Research, vol. 113, pp. 510-519, 2017.

[6] X. Zhang, "Vibration control method for a crawler-type combine harvester," Emirates Journal of Food and Agriculture, vol. 30, no. 10 , pp. $873-882,2018$.

[7] S. Chuan-Udom, "Development of a cutter bar driver for reduction of vibration for a rice combine harvester," Asia-Pacific Journal of Science and Technology, vol. 15, no. 7, pp. 572-580, 2017.

[8] K. Yoshino, H. Ishii, and K. Nishimura, "Method for monitoring rotary shaft rotation speed fluctuation in machine tool, monitor apparatus, and machine tool," U.S. Patent, no. 9010453, 2015.

[9] H. Solmaz and H. Karabulut, "A mathematical model to investigate the effects of misfire and cyclic variations on crankshaft speed fluctuations in internal combustion engines," Journal of Mechanical Science and Technology, vol. 29, no. 4, pp. 1493-1500, 2015.

[10] M. Felber and J. Pfeiffer, "Method and device for recognizing rotational speed/torque fluctuations in a drive device," U.S. Patent, no. 9250157, 2016.

[11] Y. Yang, X. J. Dong, Z. K. Peng, W. M. Zhang, and G. Meng, "Vibration signal analysis using parameterized time-frequency method for features extraction of varying-speed rotary machinery," Journal of Sound and Vibration, vol. 335, pp. 350-366, 2015.

[12] X. Wang, X. Liang, G. Shu, and S. Watkins, "Coupling analysis of linear vibration energy harvesting systems," Mechanical Systems and Signal Processing, vol. 70-71, pp. 428-444, 2016.

[13] S. Brischetto, F. Tornabene, N. Fantuzzi, and E. Viola, "3D exact and 2D generalized differential quadrature models for free vibration analysis of functionally graded plates and cylinders," Meccanica, vol. 51, no. 9, pp. 2059-2098, 2016.

[14] Y. S. Zhou, J. Zhang, X. Li, J. R. Yue, G. B. Xia, and W. Z. Yang, "Modal analysis of rasp bar type roller based on ANSYS-Workbench," Agricultural Science \& Technology and Equipment, vol. 261, no. 3, pp. 25-27, 2016.

[15] Q. Wu, Y. Sun, W. Chen, G. Chen, Q. Bai, and Q. Zhang, "Effect of motor rotor eccentricity on aerostatic spindle vibration in machining processes," Proceedings of the Institution of Mechanical Engineers, Part C: Journal of Mechanical Engineering Science, vol. 232, no. 7, pp. 1331-1342, 2018.

[16] G. Chen, Y. Sun, C. An, F. Zhang, Z. Sun, and W. Chen, "Measurement and analysis for frequency domain error of ultra-precision spindle in a flycutting machine tool," Proceedings of the Institution of Mechanical Engineers, Part B: Journal of Engineering Manufacture, vol. 232, no. 9, pp. 1501-1507, 2018.

[17] M. Eissa and N. Saeed, "Nonlinear vibration control of a horizontally supported Jeffcott-rotor system," Journal of Vibration and Control, vol. 24, no. 24, pp. 5898-5921, 2018.

[18] J. Liu and Y. Shao, "Vibration modelling of nonuniform surface waviness in a lubricated roller bearing," Journal of Vibration and Control, vol. 23, no. 7, pp. 1115-1132, 2017.

[19] A. H. Lee, R. L. Campbell, and S. A. Hambric, "Coupled delayed-detached-eddy simulation and structural vibration of a self-oscillating cylinder due to vortex-shedding," Journal of Fluids and Structures, vol. 48, pp. 216-234, 2014.
[20] R. Bourguet and D. Lo Jacono, "Flow-induced vibrations of a rotating cylinder," Journal of Fluid Mechanics, vol. 740, pp. 342-380, 2014.

[21] Y. H. Li and S. L. Zhu, "Analysis on shafting vibration of pump unit based on shafting stiffness calculation," Journal of Drainage and Irrigation Machinery Engineering, vol. 35, no. 7, 2017.

[22] M. Bermejo, A. P. Santos, and J. M. Goicolea, "Development of practical finite element models for collapse of reinforced concrete structures and experimental validation," Shock and Vibration, vol. 2017, Article ID 4636381, 8 pages, 2017.

[23] S. Zhang and Z. Zhang, "Research on the field dynamic balance technologies for large diesel engine crankshaft system," Shock and Vibration, vol. 2017, Article ID 7150472, 10 pages, 2017.

[24] B. Bai and L. X. Zhang, "Dynamic response of hydro-turbine set shaft system under stochastic hydraulic excitation," Journal of Drainage and Irrigation Machinery Engineering, vol. 35, no. 5, 2017.

[25] Z. Tang, H. T. Zhang, and Y. P. Zhou, "Unbalanced vibration identification of tangential threshing cylinder induced by rice threshing process," Shock and Vibration, vol. 2018, Article ID 4708730, 14 pages, 2018.

[26] Y. J. Chen, Y. Zheng, and K. Kan, "Modal analysis of axial-flow pump rotor system in water," Journal of Drainage and Irrigation Machinery Engineering, vol. 35, no. 2, 2017.

[27] G. Chen, Y. Sun, F. Zhang, C. An, W. Chen, and H. Su, "Influence of ultra-precision flycutting spindle error on surface frequency domain error formation," International Journal of Advanced Manufacturing Technology, vol. 88, no. 9-12, pp. 3233-3241, 2017.

[28] M. R. Khoshdarregi, S. Tappe, and Y. Altintas, "Integrated five-axis trajectory shaping and contour error compensation for high-speed CNC machine tools," IEEE/ASME Transactions on Mechatronics, vol. 19, no. 6, pp. 1859-1871, 2014.

[29] A. Saito, M. P. Castanier, and C. Pierre, "Effects of a cracked blade on mistuned turbine engine rotor vibration," Journal of Vibration and Acoustics, vol. 131, no. 6, article 061006, 2009.

[30] Z. Tang, Y. M. Li, R. Wang, and J. S. Chen, "Experimental study of multi-source dynamic load of combine harvester in rice harvesting," International Agricultural Engineering Journal, vol. 25, no. 3, pp. 46-52, 2016.

[31] Y. Cao, R. Zhang, W. Zhang, and J. Wang, "Vibration characteristics analysis of cylindrical Shell-plate coupled structure using an improved fourier series method," Shock and Vibration, vol. 2018, Article ID 9214189, 19 pages, 2018.

[32] M. Brazinskas, S. Prior, and J. Scanlan, “An empirical study of overlapping rotor interference for a small unmanned aircraft propulsion system," Aerospace, vol. 3, no. 4, p. 32, 2016.

[33] M. R. Shamim and D. V. Berezhnoi, "Investigation of deformation at a centrifugal compressor rotor in process of interference on shaft," Materials Science and Engineering Conference Series, vol. 158, no. 1, article 012083, 2016.

[34] Y. Zhang, A. H. Guan, Q. Qian, Y. B. Lai, and J. Li, "The beat frequency phenomenon in the vibration fault of asynchronous motor," Modern Industrial Economy and Informationization, vol. 8, no. 8, pp. 90-91, 2018. 


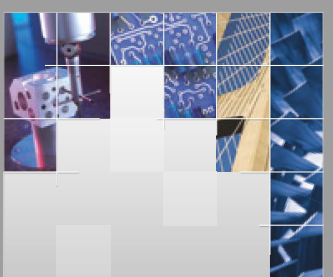

\section{Enfincering}
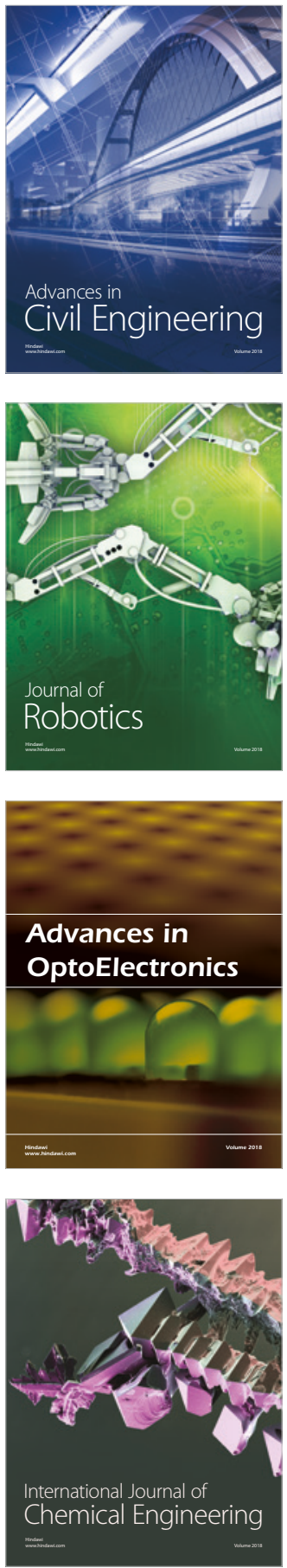

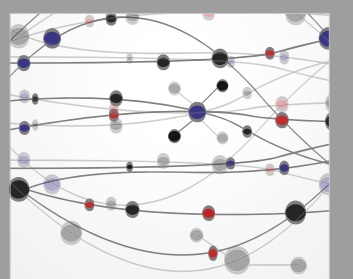

\section{Rotating \\ Machinery}

The Scientific World Journal

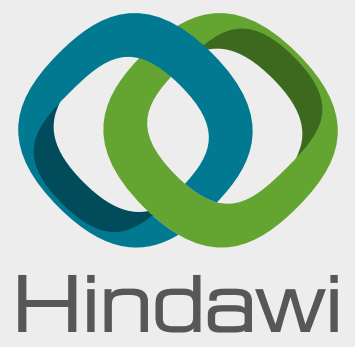

Submit your manuscripts at

www.hindawi.com
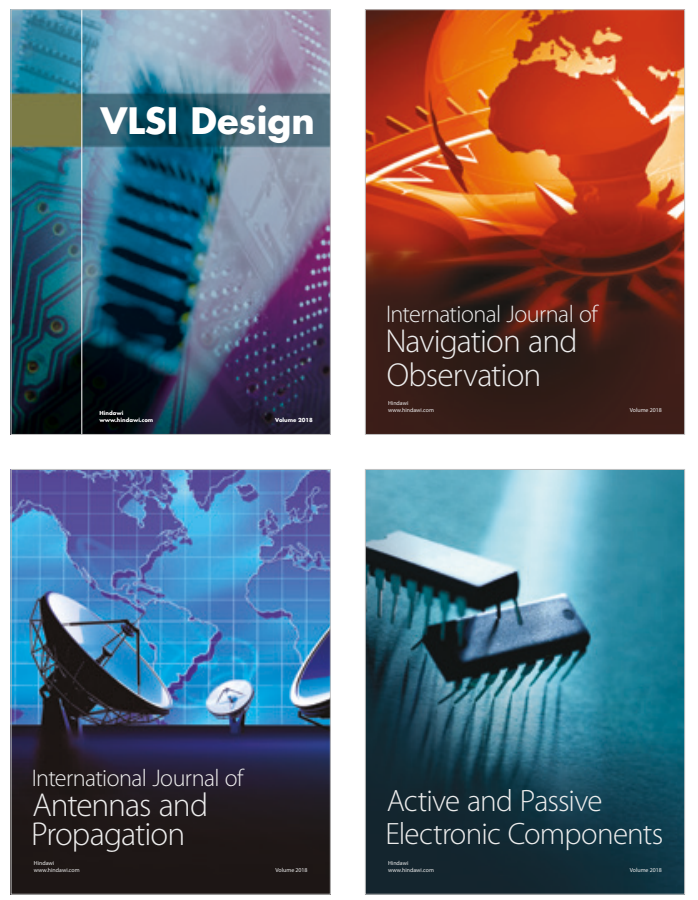
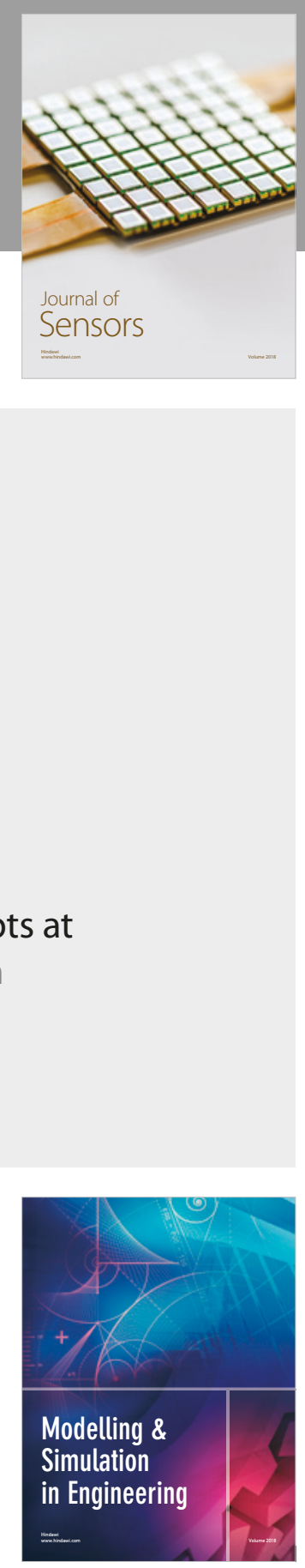

\section{Advances \\ Multimedia}
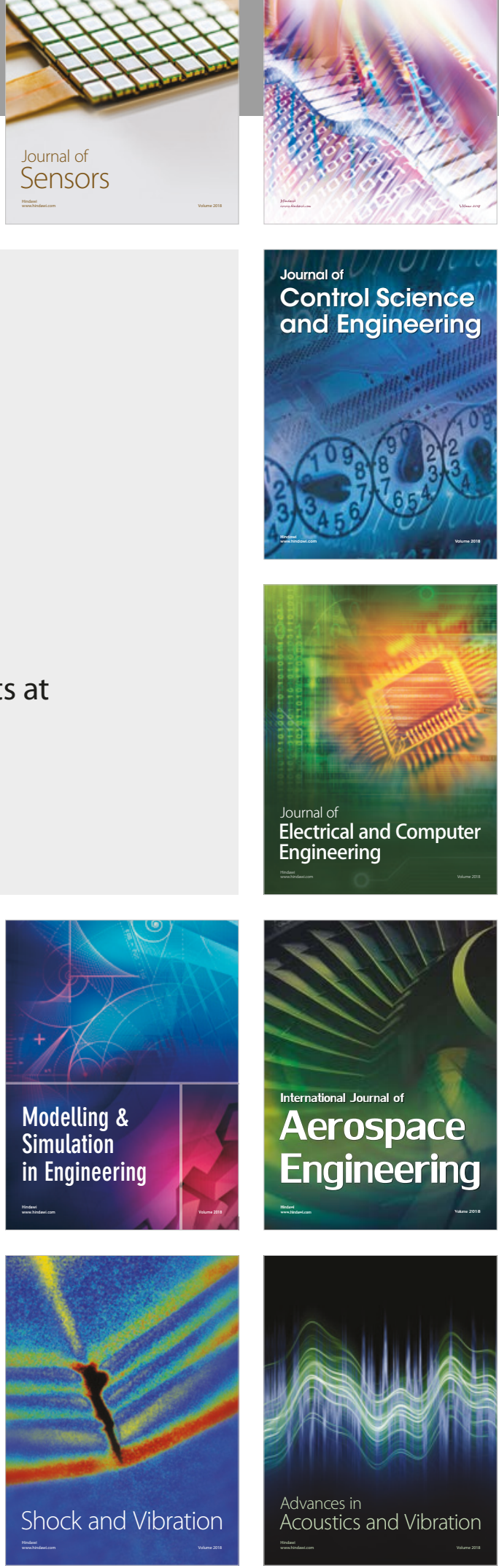